\section{Tenuazonic acid: a promising antitubercular principle from Alternaria alternata}

\author{
Visalakchi Sonaimuthu, ${ }^{1}$ Swati Parihar, ${ }^{2}$ \\ Jay Prakash Thakur, ${ }^{2}$ Suaib Luqman, ${ }^{2}$ \\ Dharmendra Saikia, ${ }^{2}$ \\ Chandan S. Chanotiya, ${ }^{2}$ \\ Muthumary Jhonpaul, ${ }^{1}$ \\ Arvind Singh Negi \\ 'Centre for Advanced Studies in Botany, \\ University of Madras, Guindy Campus, \\ Chennai, Tamil Nadu; \\ ${ }^{2}$ Central Institute of Medicinal and \\ Aromatic Plants (CIMAP-CSIR), Kukrail \\ Picnic Spot Road, Lucknow, India
}

\begin{abstract}
Bioactivity guided isolation of dichloromethane extract of Alternaria alternata identified tenuazonic acid (1) as potentially active against Mycobacterium tuberculosis $\mathrm{H} 37 \mathrm{Rv}$, MIC at $250 \mu \mathrm{g} / \mathrm{mL}$ concentration. This active metabolite 1, was also evaluated for osmotic hemolysis using the erythrocyte as a model system. It was observed that this fungal metabolite showing antitubercular activity exhibited concentration dependent toxicity to human erythrocytes.
\end{abstract}

\section{Introduction}

Fungi play an important role among a variety of species produced by nature. ${ }^{1}$ Fungi produce and metabolize a broad range of simple to very complex organic compounds. ${ }^{1}$ These fungal metabolites are generally termed as mycotoxins due to their toxic effects and risk to humans. ${ }^{2}$ Ironically, in the recent past these fungal metabolites have become an interesting source of molecules due their possible uses as therapeutics. ${ }^{1}$ Alternaria is a widespread fungal genus known for the high pathogenicity of some of its members and several species are known as plant pathogens.${ }^{3,4}$ Alternaria alternata is an opportunistic pathogenic fungi on numerous hosts causing leaf spots, rots and blights on many plant parts. A number of metabolites are already reported from this fungus. ${ }^{5}$

In the present study, we have investigated antitubercular activity of the endophytic fungal strain Alternaria alternata, which was isolated from the leaves of the Indigofera enneaphylla. On systematic chromatographic isolation, we found tenuazonic acid (1, TA) as bioactive compound responsible for antitubercular activity.

\section{Materials and Methods}

\section{General}

All the laboratory chemicals were purchased from Thomas Baker, India. The Nuclear Magnetic Resonance (NMR) solvents were procured from Sigma Aldrich USA. Thin layer chromatography (TLC) was done on Merck aluminium sheet thin layer chromatography (TLC, UV254nm) plates. NMR spectra were measured on a Bruker Avance $300 \mathrm{MHz}$ instrument with TMS as an internal standard. Electron Impact ionization mass (EI mass) spectra were recorded on Perkin-Elmer Turbo Mass GC-MS system after dissolving the compounds in methanol.

\section{Isolation of endophytic fungus from medicinal plant}

The healthy medicinal plant (Indigofera enneaphylla L.) leaf samples were obtained from Herbal Garden, Centre for Advanced Studies in Botany (CAS in Botany), Guindy Campus, University of Madras, Chennai, India. Alternaria alternata SVJM015 was isolated from surface-treated leaves of $I$. enneaphylla and the fungus was identified using standard monographs. The identified strain (A. alternata SVJM015) was deposited to Madras University Botany Laboratory (MUBL), CAS in Botany, University of Madras, Chennai - 600025.

The collected leaf samples were surface sterilized for the isolation of endophytic fungi. The healthy leaf samples were first washed in running tap water and processed as follows. The samples were sliced into small segments (approximately $0.5 \mathrm{~cm}^{2}$ ) to screen the presence of endophytic fungal isolates. Leaf segments were surface sterilized with $70 \%$ ethanol for 5 sec., immersed in $4 \% \mathrm{NaOCl}$ for $90 \mathrm{sec}$., rinsed in sterile distilled water and then dried on sterile filter paper. The surface sterilized plant segments were inoculated on to a petriplates containing potato dextrose agar (PDA) medium amended with streptomycin $(30 \mu \mathrm{g} / \mathrm{mL})$. The petriplates were sealed with parafilm ${ }^{\mathrm{TM}}$ and incubated at $25 \pm 1^{\circ} \mathrm{C}$ in a growth chamber with $12 \mathrm{~h}$ light followed by 12 $\mathrm{h}$ of dark regime and checked from the second day for fungal growth. ${ }^{6}$ The hyphae growth was observed from the tissues on PDA plates, immediately it's were transferred in to fresh PDA plates for further studies.

Molecular characterization of endophytic fungal isolate ( $A$. alternata SVJM015)

The fungal DNA was amplified using the Internal Transcribe Sequencer (ITS) primers such as ITS1 (F 5'-TCC GTA GGT GAA CCT GCG G -3') and ITS4 (R 5'-TCC TCC GCT TAT TGA
Correspondence: Arvind Singh Negi, Chemical Sciences Division, Central Institute of Medicinal and Aromatic Plants (CIMAP-CSIR), Kukrail Picnic Spot Road, Lucknow-226 015, India;

E-mail: arvindcimap@rediffmail.com

Key words: alternaria alternata, tenuazonic acid, Mycobacterium tuberculosis, tuberculosis, antitubercular, toxicity, erythrocyte fragility.

Received for publication: 26 July 2011. Accepted for publication: 16 September 2011.

This work is licensed under a Creative Commons Attribution NonCommercial 3.0 License (CC BYNC 3.0).

CCopyright V. Sonaimuthu et al., 2011

Licensee PAGEPress, Italy

Microbiology Research 2011; 2:e17

doi:10.4081/mr.2011.e17

TAT GC-3') for the molecular identification. ${ }^{7}$ Amplification was carried out with $20-\mu \mathrm{L}$ reaction mixture containing $1 \mathrm{X}$ PCR buffer, $2.5 \mu \mathrm{M}$ $\mathrm{MgCl}_{2}, 0.6 \mu \mathrm{M}$ of each dNTPs, $0.25 \mu \mathrm{M}$ of each primers, $1.25 \mathrm{U}$ Taq polymerase and $4 \mathrm{ng}$ gDNA. The reagents were obtained from QIAGEN (QIAGEN, Chatsworth, CA, USA). PCR amplification was performed in a T-Gradient thermal cycler (Biometra, Gottingen, Germany). The amplification starts with initial denaturation at $95^{\circ} \mathrm{C}$ for 3 min., followed by 34 cycles with denaturation at $94^{\circ} \mathrm{C}$ for $15 \mathrm{sec}$., annealing at $55^{\circ} \mathrm{C}$ for 45 sec., extension at $72^{\circ} \mathrm{C}$ for $55 \mathrm{sec}$. and the final extension at $72^{\circ} \mathrm{C}$ for 7 min. Negative control (no template DNA) was included in this study. The amplified PCR products were purified with QIAquick PCR purification kit (QIAGEN). The purified PCR products were sequenced; the sequence data was BLAST and submitted with NCBI database (National Centre for Biotechnology Information, USA) for GenBank accession number.

\section{Fungal culturing and extraction}

The endophytic isolate, A. alternata SVJM015 was selected for the screening of bioactive compounds production and grown in 4 L Hopkins flasks containing 2 L of M1D medium supplemented with soytone $(1 \mathrm{~g} / \mathrm{L})$ and incubated at $25^{\circ} \mathrm{C} \pm 1$ for 21 days in still culture. ${ }^{8}$ After incubation, the fungal culture was passed through a four layered of cheesecloth.

Then, the culture filtrate was extracted with two equal volumes of methylene chloride and the organic phase was evaporated to dryness under reduced pressure at $35^{\circ} \mathrm{C}$. The residue obtained was further processed for purification. 


\section{Bioactivity guided isolation of fungal metabolites}

The crude mass obtained $(315 \mathrm{mg}$ ) from methylene chloride was charged on silica gel (100-200 mesh, 2x40 cm glass) column and eluted successively with hexane $(200 \mathrm{~mL})$, chloroform-hexane ( $20 \%$ x $500 \mathrm{~mL})$ and subsequently increasing polarity by adding chloroform ( $40 \%, 60 \%$ and so on). At $60 \%$ chloroformhexane compound A $(\sim 4 \mathrm{mg}, 2)$ was obtained as oil. At $80 \%$ chloroform-hexane another compound B ( 42 mg, 1) was obtained as oil.

\section{In vitro antimycobacterial assay by BACTEC radiometric susceptibility assay}

The antimycobacterial assay was done radiometrically as per previously reported method. ${ }^{9,10}$ Rifampicin (Sigma Chemicals, USA), a standard drug for tuberculosis was used as positive control.

\section{Determination of erythrocytes osmotic fragility}

The in vitro erythrocyte osmotic fragility test was done as per previously described procedure. ${ }^{11,12,13}$ Curcumin was used as erythrocyte membrane stabilizer (positive control), while hydrogen peroxide was used as erythrocyte fragility inducer (Figure 1).

\section{Results and Discussion}

On chromatographic purification of methylene chloride soluble fraction of $A$. alternata resulted in identifying TA $(1,5 \mathrm{~S}, 6 \mathrm{~S}$-3-acetyl-5sec-butyl-4-hydroxypyrrolidone-2,4-dione) as active constituent against Mycobacterium tuberculosis. TA obtained as oil, showed molecular ion peak at $197\left[\mathrm{M}^{+}\right]$and $198[\mathrm{M}+1]^{+}$ consistent to molecular formulae $\mathrm{C}_{10} \mathrm{H}_{15} \mathrm{NO}_{3}$. In ${ }^{13} \mathrm{C}$ NMR, compound 1 showed 3 methyls, one methylene, two methines, and four quaternary carbons. Compound 1 was ascertained as tenuazonic acid on the basis of ${ }^{1} \mathrm{H}$ NMR, ${ }^{13} \mathrm{C}$ NMR, distortionless enhancement of polarization transfer (DEPT)-90, DEPT-135. The ${ }^{1} \mathrm{H}$ and ${ }^{13} \mathrm{C}$ NMR spectral data of TA are well in agreement with the earlier published data ${ }^{11}$ (Table 1). Another compound 2 was also isolated as oil, but due to insufficient quantity, its complete structure could not be ascertained. Antitubercular compounds from this fungus have not been reported previously. In this study, antitubercular activity of TA was found to be twice as active as the dichloromethane extract. The antitubercular activity of dichloromethane extract was at $500 \mu \mathrm{g} / \mathrm{mL}$ against Mycobacterium tuberculosis $\mathrm{H}_{37} \mathrm{Rv}$ strain through BACTEC assay. The minimum inhibitory concentration (MIC) of test compound was noted on the basis of GI (growth index) value. The antitubercular activity of TA was found to be $250 \mu \mathrm{g} / \mathrm{mL}$ against the same strain of M. tuberculosis (Table 2).

Antifungal, antibacterial, cytotoxic and antiviral properties of TA are previously reported. TA has exhibited antibiotic activity in inhibiting Paenibacillus larvae, which is the causal agent of American foulbrood, a honeybees' disease. ${ }^{14}$ Recently, some of the analogues of TA have been reported as antifungal and herbicidal agents ${ }^{15}$ We confirm here antitubercular activity of TA which is not reported earlier.

In conclusion, on bioactivity guided isolation tenuazonic acid has been reported as antitubercular constituent in A. alternata. This compound exhibited toxicity to human erythrocytes in a concentration dependent manner i.e. higher concentration of the compound increased the fragility whereas, lower concentration did not. This may provide some structural clues for future development of new antitubercular agents.

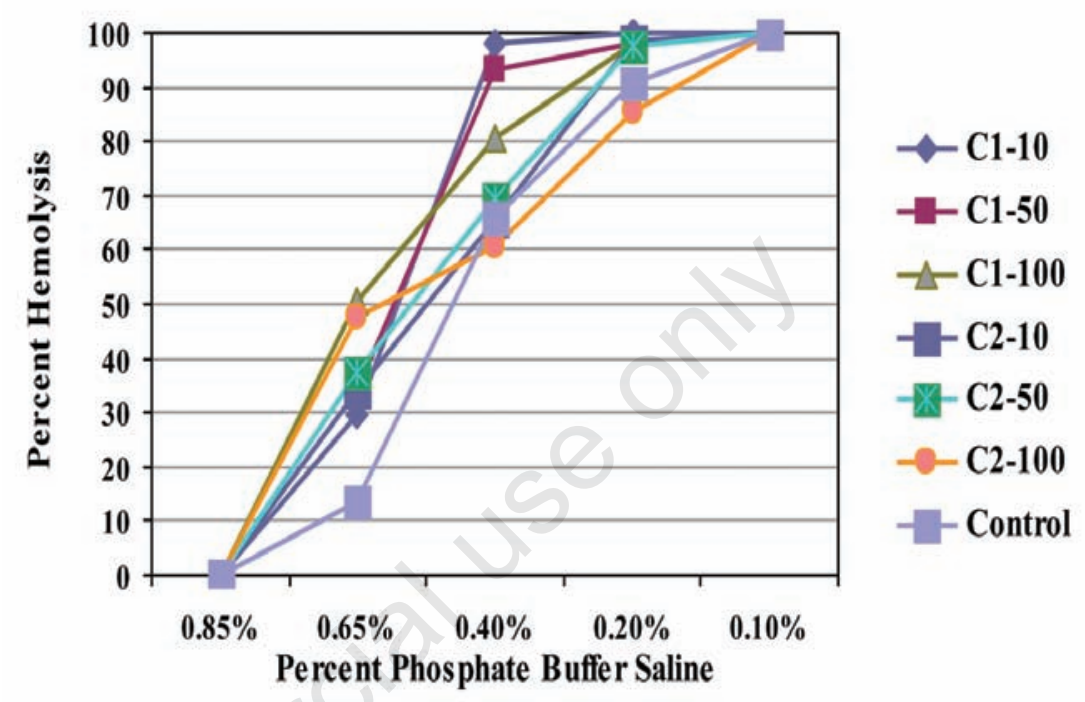

Figure 1. Osmotic fragility curve of erythrocyte treated with compounds 1 and 2.

Table 1. Spectral data of Tenuazonic acid (1).

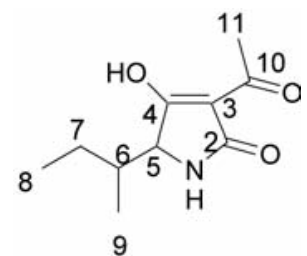

\begin{tabular}{|c|c|c|c|}
\hline Assignments & $\begin{array}{c}{ }^{13} \mathrm{C} \\
\left(\mathrm{CDCl}_{3}, 75 \mathrm{MHz}\right) \\
\delta \text { values }(\mathrm{ppm})\end{array}$ & $\begin{array}{c}\text { Compound } 1 \\
1 \mathrm{H} \\
\left(\mathrm{CDCl}_{3}, 300 \mathrm{MHz}\right) \\
\delta \text { values (ppm) }\end{array}$ & $\begin{array}{c}\text { Mass } \\
\text { (EI Mass) }\end{array}$ \\
\hline $\mathrm{N} 1$ & -- & 7.79 (s, 1H, exchangeable, $\mathrm{NH})$ & \multirow{11}{*}{$\begin{array}{c}197[\mathrm{M}]^{+}, 198 \\
{[\mathrm{M}+1]^{+}, 195[\mathrm{M}-} \\
2]^{+}, 168[\mathrm{M}-29]^{+} .\end{array}$} \\
\hline $\mathrm{C} 2$ & $175.63(\mathrm{QC})$ & --- & \\
\hline $\mathrm{C} 3$ & $102.45(\mathrm{QC})$ & --- & \\
\hline $\mathrm{C} 4$ & $184.20(\mathrm{QC})$ & 11.55 (exchangeable, $\mathrm{OH}$ ) & \\
\hline $\mathrm{C} 5$ & 67.23 & $3.79(\mathrm{CH})$ & \\
\hline $\mathrm{C} 6$ & 36.83 & $2.51(\mathrm{CH})$ & \\
\hline $\mathrm{C} 7$ & 23.46 & $1.23(\mathrm{CH} 2)$ & \\
\hline $\mathrm{C} 8$ & 11.51 & 0.998 (CH3) & \\
\hline $\mathrm{C} 9$ & 15.67 & $1.02(\mathrm{CH} 3)$ & \\
\hline $\mathrm{C} 10$ & $195.71(\mathrm{QC})$ & --- & \\
\hline $\mathrm{C} 11$ & 19.34 & $2.46(\mathrm{CH} 3)$ & \\
\hline
\end{tabular}

Assignments are based on 1H, 13C, DEPT 135 \& DEPT 90 experiments. $\mathrm{QC}=$ quaternary carbon, $\mathrm{OH}=$ hydroxyl group, $\mathrm{NH}=$ amine group. 
Table 2. Antimycobacterial activity of compounds and extract against $M$. tuberculosis H37Rv.

\begin{tabular}{ccc} 
S. no. & Compound no. & $\begin{array}{c}\text { Minimum Inhibitory Concentration (MIC) } \\
\mu \mathrm{g} / \mathrm{mL}\end{array}$ \\
1. & Dichloromethane extract & 500 \\
2. & 1 & 250 \\
\hline 3. & 2 & Inactive \\
4. & Rifampicin & 2 \\
\hline
\end{tabular}

\section{References}

1. Brase S, Encinas A, Keck J, Nising CF. Chemistry and biology of mycotoxins and related fungal metabolites. Chem Rev 2009;109:3903-90.

2. Bannett JW, Klich M. Mycotoxins. Clin Microbiol Rev 2003;16:497-516.

3. Gamboa-Angulo MM, Alejos-Gonza'lez F, Escalante-Erosa F, et al. Novel dimeric metabolites from Alternaria tagetica. J Nat Prod 2000;63:1117-20.

4. Kjer J, Wray V, Edrara-Ebel R, et al. Xanalteric acids I and II and related phenoilc compounds from an endophytic alternaria sp. Iolated from the Mangrove plant Sonneratia alba. J Nat Prod 2009;
72:2053-57.

5. Aly AH, Edrada-Ebel R, Indriani ID, et al. Cytotoxic metabolitesfrom the fungal endophyte Alternaria sp. and their subsequent detection in its host plant Polygonum senegalense. J Nat Prod 2008; 71:972-80.

6. Bills GF, Polishook JD. Recovery of endophytic fungi from Chamaecyparis thyoides. Sydowia 1992;44:1-12.

7. White TJ, Burns T, Lee S, Taylor J. Amplification and direct sequencing of fungal ribosomal RNA genes for phylogenetics. In: PCR protocols: a guide to methods and applications. Innis MA, Gelfand GH, Sninsky JJ, White TJ (editors). San Diego, CA: Academic Press; 1990. pp. 315322 .

8. Pinkerton R, Strobel G. Serinol as an activator of toxin production in attenuated cultures of Helminthosporium sacchari. Proce Natl Acad Sci USA 1976;73: 4007-11.

9. Siddiqi SH. BACTEC 460TB System. Product and procedure manual. Revision E. Sparks, MD: Becton Dickinson Diagnostic Instrument Systems; 1996.

10. Petersdorf RG, Sherris JC. Methods and significance of in vitro testing of bacterial sensitivity to drugs. Am J Med 1965;39: 766-79.

11. Luqman S, Rizvi SI. Asia Pacific J Pharmacol 2004;16:53-5.

12. Luqman S, Obli Prabu KV, Pal A, et al. Natural Product Communications 2006; 1: 481-6.

13. Dacie JV, Lewis SM. Practical hematology. 6th edition. Orient Longman; 1984. pp. 152-156.

14. Gallardo G, Pena NI, Chacana P, et al. LTenuazonic acid, a new inhibitor of Paenibacillus Larvae. World J Microbiol Biotechnol 2004;20:609-12.

15. Wang XF, Si TF, Li QBet al. Synthesis, characterisation and biological activity of novel (5RS,6S)-5-sec-butyl-3-(1-substitutedamine)ethylidene-1H-pyrrolidine-2,4-diones. Arkivoc 2010;(ii):31-48. 